\title{
0 homem da moral e o homem da ética em Lavoura Arcaica
}

\author{
The man of morals and the man of ethics in Lavoura Arcaica
}

Alessandra Aguiar Vieira

Bacharel em Psicologia pela Universidade Federal de Minas Gerais (UFMG), bolsista CNPq, Belo Horizonte, MG - Brasil, e-mail: ale.aguiarvieira@yahoo. com.br

Recebido: 17/02/2011 Received: 02/17/2011

Aprovado: $13 / 04 / 2011$ Approved: 04/13/2011

\section{Resumo}

Este artigo visa a analisar alguns aspectos do livro Lavoura Arcaica, escrito por Raduan Nassar, publicado em 1975 e posteriormente traduzido para o espanhol, alemão e francês. Esse livro é considerado sua obra-prima e gerou considerável interesse dos críticos literários graças ao seu caráter inovador, marcado por um discurso confessional que é imposto aos seus leitores, convidando-os a uma viagem aos aspectos mais íntimos e profundos da existência humana. Nesta medida, este trabalho diz respeito à complexa construção da identidade social e alteridade nos personagens envolvidos. Analisamos como a identidade pressuposta é quebrada pelo personagem André ao longo do romance e como ela o impulsiona a defender a sua própria alteridade - um movimento que provoca a divisão e a ruptura de valores naturalizados no seio da família. No entanto, ao questionar "os limites da fazenda", André entra em um constante embate retórico com seu pai Yohama, o que pode representar, no ponto de vista de Sueli Rolnik, o encontro do homem da moral e o homem da ética.

Palavras-chave: Lavoura Arcaica. Identidade pressuposta. Alteridade. Homem da ética. Homem da moral.

\section{Abstract}

This paper aims to analyze some aspects of the book Lavoura Arcaica, written by Raduan Nassar, published in 1975 and since then translated into Spanish, German, and French. This book is considered his masterpiece and has generated considerable literary critical interest because of its innovative character, marked by a confessional discourse that is imposed onto his readers, inviting them into a trip throughout the most intimate and profound aspects of human existence. This work concerns the complex construction of social identity and alterity by its characters. We analyze how assumed identity is broken down by Andrés character along the course of the novel and how this pushes him to defend his own alterity - a movement that causes division and rupture of naturalized values within his family. However, by putting "the boundaries of the farm" into question, André comes into constant rhetorical clash with his father Yohama, who may represent, in Sueli Rolnik's point of view, the meeting of the man of morals and the man of ethics.

Keywords: Lavoura Arcaica. Assumed identity. Alterity. Man of morals. Man of ethics. 


\section{Introdução}

Romance de estreia do escritor paulista Raduan Nassar, Lavoura Arcaica foi publicado pela primeira vez em 1975, tornando-se, desde o início, alvo de grande interesse da crítica literária. Conforme nos aponta Sedlmayer-Pinto (1997), tal obra rompeu com a produção literária dos anos 1970 e 1980 e que se convencionou chamar "literatura pós-moderna". Assim, Nassar afastou-se do cenário urbano, rico por imagens tecnológicas, permeado pelo naturalismo dos 'romances-reportagem', passando a cultivar uma linguagem profunda em que é possível escutar "ecos barrocos". Segundo tal autora, "apesar de Lavoura Arcaica resgatar muitos textos alheios, o romance traz uma linguagem tão convulsionada e percorre um trajeto tão singular na literatura brasileira que, ao tentarmos contextualizá-lo, percebemos ser este um romance solitário" (SedlmayerPinto, 1997, p. 21).

Conforme se observa, essa discrepância da obra de Raduan Nassar diante do que era produzido em sua época, reflete a sua maneira peculiar de perceber e utilizar-se da literatura. Nassar rejeitava qualquer forma de produção que se embasasse meramente em ideias advindas de teorias literárias. Nesse sentido, defende a existência de um "texto vida": "aquele que transcende a preocupação formal e linguística e busca a interlocução com o leitor" (Sedlmayer-Pinto, 1997, p. 25).

Conforme Villaça (Rodrigues, 2006, p. 10), tal obra de Nassar impressiona, pois

é do tipo que, além de não fazer vistas grossas à densidade mais íntima e problemática das experiências, busca, para narrá-las, a competência específica de quem as vive e as expressa naquela fronteira em que poesia e prosa, natureza e história, instinto e consciência, intimidade e socialização tanto mais se confundem quanto mais pretendem proclamar-se em separado.

Com boa recepção pela crítica literária, em 1976 Nassar recebeu o prêmio Coelho Neto pela Academia Brasileira de Letras. Contudo após a publicação de Um copo de cólera (1978), Nassar interrompeu temporariamente sua produção, calando-se "numa atitude que se assemelha a uma recusa" (SedlmayerPinto, 1997, p. 23).

A presença de uma narrativa difusa (não linear), acompanhada por uma linguagem poética e profunda, produz no leitor de Lavoura Arcaica sensações diversificadas, que possibilita a desestabilização de valores identitários até então estáticos. Essa turbulência que permeia a narrativa é explicitada por Villaça (Rodrigues, 2006, p. 9):

Lavoura Arcaica é um romance exigente, por várias razões. Conta, em primeiro lugar, com um leitor cuja sensibilidade se ative plenamente na sintonia fina dos impulsos rítmicos-melódicos, os quais estão na base da narração e constituem uma modalidade de fala e uma expectativa de escuta peculiares ao discurso da poesia. A tonalidade confessional do narrador-protagonista dá presença viva a uma voz que sofre tudo o que diz, e diz tudo num registro de extremos.

Nesta medida, e tendo em vista a própria complexidade da trama desenvolvida, este trabalho tem como objetivo apresentar uma discussão acerca da construção da identidade social nos personagens envolvidos, apreendendo, principalmente, a dialética do discurso do pai e do filho André. Assim, pretende-se compreender o movimento de diferenciação do personagem principal, seus avanços e retrocessos, na busca irrompida de "ser profeta de sua própria história” (Nassar, 2005, p. 87).

\section{A Partida: a busca incessante de romper "os limites da fazenda"}

Que rostos mais coalhados, nossos rostos adolescentes em volta daquela mesa: o pai à cabeceira, o relógio de parede às suas costas, cada palavra sua ponderada pelo pêndulo, e nada naqueles tempos nada nos distraindo tanto como os sinos graves marcando as horas (Nassar, 2005, p. 51).

A história narrada pelo livro divide-se em duas partes principais, a partida e o retorno do narrador personagem André à casa dos pais. André é um jovem do meio rural que resolve abandonar a família para ir morar em uma pequena cidade próxima. A razão pela qual ele abandona "os limites da fazenda" relaciona-se ao caráter asfixiante do seu mundo social, a família patriarcal, no qual a rigidez moral impedia-o de ser livre e 'dono de sua própria história'. Acometido por um amor incestuoso pela mãe e pela paixão desenfreada pela irmã Ana, André resolve se distanciar do universo hostil de sua família, marcado 
pela severidade e austeridade da figura do pai Yohana. Com a sua saída de casa, o precário equilíbrio da família foi se desvanecendo e, diante disso, Pedro, o filho mais velho, foi incumbido de trazer de volta à família o filho 'acometido pelo sopro virulento' da rebeldia.

A narrativa inicia-se com a visita de Pedro a um quarto de pensão onde André estava vivendo. Essa visita, até então desavisada, leva o nosso personagem principal a uma retrospectiva aos momentos em que esteve presente no seio da família, começando pela infância até os últimos minutos em que 'sentou à mesa do pai'. Nesse ponto, André apresenta-nos sua família, enfatizando o ritual da partilha do pão à mesa com a presença dos irmãos e da mãe, todos com os olhos abaixados, ouvindo os sermões do pai. Nessa passagem, André compara a família a uma árvore, na qual:

0 galho à direita (onde estaria o irmão mais velho) seria um desenvolvimento espontâneo do tronco desde as suas raízes. Já à esquerda (conteria André, a mãe e o filho mais novo) traria o estigma de uma cicatriz, como se a mãe, onde começa o segundo tronco, fosse a anomalia, uma protuberância mórbida pela carga do afeto (Nassar, 2005, p. 154).

Nessa medida, percebemos a importância da 'família' no livro, similar a um universo social fechado, no qual a figura da mulher e dos filhos que fogem à regra naturalizada são estigmatizados. A família, dessa forma, restringe-se aos limites da fazenda e constitui um mundo particular regido pela tradição, reiterada a cada geração pela figura paterna. Nessa estrutura familiar, por conseguinte, a identidade do pai confunde-se com o próprio papel social a que ele pertence, aspecto este bastante enfatizado em toda a história, sobretudo no que se refere à representação da figura do avô, um ser hostil no qual apenas se via o 'brilho do colar de ouro'.

Desse modo, o pai de André é aquele que substitui o avô na estruturação da família, assim como Pedro irá assumir o lugar do pai algum dia. É possível perceber nessa transposição de gerações uma reposição da identidade pressuposta, ou seja, de um conjunto de expectativas, papéis sociais, que são atribuídos, a princípio, a alguém que nasce. Segundo Ciampa (2004, p. 66), antes de nascer, o filho é representado como parte de uma família, filho de um pai e de uma mãe, porém, a identidade do bebê só se formará a partir do momento em que as relações nas quais esteja envolvido concretamente confirmem essa representação através de comportamentos que reforcem sua conduta como filho e assim por diante.

Assim, tanto aquilo que era esperado do pai pelo avô quanto de Pedro pelo pai, a identidade pressuposta será confirmada a cada momento, por meio da execução dos papéis sociais a ele relacionados. Cabe destacar também que "a identidade pressuposta, por ser reposta a cada momento é vista como dada - e não como se dando num contínuo processo de identificação" (Ciampa, 2004, p. 66). Esse aspecto explicitado anteriormente é bastante visível em todo o livro no que se refere, principalmente, aos diálogos do pai, nos quais a moral da família é vista de forma naturalizada, estática e sacralizada. Nessa medida, reatualiza-se a partir de rituais sociais uma identidade pressuposta, "que assim é reposta como algo já dado, retirando, em consequência, o seu caráter de historicidade, aproximando-a mais da noção de um mito que prescreve as condutas concretas, reproduzindo o social" (Ciampa, 2004, p. 66).

Nessa vertente, observa-se que os sermões do pai Yohana são construídos de forma rigorosa, buscando, assim, reiterar as normas sociais, dando-lhe um caráter de verdade intransponível, com a qual André, o filho rebelde, insiste em debater-se. André demonstra que cada palavra do pai era "uma folha seca e eu nessa carreira pisoteando as páginas de muitos livros, colhendo entre gravetos este alimento ácido e virulento, quantas mulheres, quantos varões, quantos ancestrais; quanta peste acumulada, que caldo mais grosso neste fruto da família!" (Nassar, 2005, p. 88).

André percebia que quem "puxava a linha" da vida era alguém mais forte do que ele, era a força da tradição, que se reiterava no ciclo constante da família: "amor, trabalho, tempo" (Nassar, 2005, p. 181). 0 amor, como o elemento capaz de manter a união da família; o trabalho como algo que purifica as mentes e os corações das paixões mundanas e o tempo como o próprio representante da imutabilidade da existência, da verdade única das coisas. Esses três elementos, juntos, permitem compreender a dinâmica dos sermões do pai, o seu caráter universal e inquestionável. Porém era a figura do avô, o "veio ancestral" da 
família, "o guia moldado em gesso", que respondia a qualquer questão "com um arroto tosco que valia por todas as ciências, por todas as igrejas e por todos os sermões do pai: Maktub [está escrito]" (Nassar, 2005, p. 89). 0 avô que, pela simples presença, conseguia transmitir a tradição e os preceitos morais tão bem fundamentados ao longo das gerações.

Já o pai, ao tentar manter a ordem moral da família com seu discurso cristalizado, paradoxalmente revela as contradições e as incertezas da vida que ora propõe, apresentando também aos filhos o que há de mais profano e apaixonado. Em mais uma passagem, afirma o pai:

O mundo das paixões é o mundo do desequilíbrio, é contra ele que devemos esticar o arame das cercas, e com as farpas de tantas fiadas tecer um crivo estreito, e sobre este crivo emaranhar uma sebe viva, cerrada e pujante, que divida e proteja a luz calma e clara da casa, que cubra e esconda dos nossos olhos as trevas que ardem do outro lado, nenhum de nós há de transgredir essa divisa (Nassar, 2005, p. 54).

Nesse trecho podemos perceber que o pai, ao tentar negar a vida profana, contrapondo-a à vida serena e clara da casa, não deixa de tornar as 'trevas' como algo possível, instigante aos filhos. E é exatamente nessa incongruência que André encontra o caminho das paixões do corpo, fazendo delas a sua religião particular. Conforme aponta Rodrigues (2006, p. 44),

ao condenar as paixões, o pai não vê (ou não quer ver) que o seu discurso é apaixonado. Ao estabelecer tão claramente as diferenças entre luz e trevas, ao recusar terminantemente as últimas, ele também parece não se dar conta de que o excesso de luz em muitos casos pode ser cegueira, assim como as trevas podem muitas vezes ser caminho para a iluminação.

Nessa medida, podemos perceber que o discurso do pai incide sobre uma família já cindida, ou seja, uma simples presença, como era no caso do avô, não é mais suficiente para transmitir os costumes. Ao pai se impõe o discurso, o que o coloca refém das palavras, sempre tão dúbias e imprecisas.

Em suma, visualizamos nesses personagens descritos anteriormente a presença daquilo que Sueli Rolnik (1994, p. 165) chamou de Homem da moral. Este se caracteriza por conhecer os códigos, isto é, o conjunto de valores e regras de ação vigentes na sociedade, tomando como referência tais códigos. O homem da moral transita no visível, no mundo das regras, defendendo-se contra a alteridade, apresentando para isso mecanismos de defesa que o impedem de acolher "o mal-estar" produzido pelas diferenças. Assim, e tendo em vista a obra Lavoura Arcaica, as figuras do avô, do pai e de Pedro podem ser analisadas à luz de tal conceito, pois, como será demonstrado posteriormente, esses personagens não se deixam desestabilizar pelo existencialismo apelativo de André, defendendo-se de seus questionamentos a partir da hipótese de que ele 'estaria doente'.

André, em sua retrospectiva, relembra a sua infância com nostalgia, destacando seus aspectos de pureza e inocência. Bastante emocionado declara a seu irmão Pedro: "era boa a nossa infância", mas com o tempo, "uma claridade passou a me perturbar, tornei-me estranho" (Nassar, 2005, p. 25-26). Ou seja, André, com o passar dos anos, havia perdido aquilo que para ele era o mais valioso na infância: a sua candidez. Percebe-se, então, que a claridade da realidade da família estava cegando-o. Para ele, os sermões do pai já não tinham mais consistência.

Ao longo da obra, é possível notar também algumas referências à Parábola do Filho Pródigo, na qual o filho desgarrado volta para casa, sendo recebido com festa. Neste aspecto, cabe destacar que a trama do livro é considerada por alguns críticos como uma versão ao avesso dessa parábola, já que o filho fora trazido ao lar pelo irmão, e não por sua vontade própria ou arrependimento. Paralelamente, observa-se também fortes traços de religiosidade ao longo do livro, principalmente nos sermões do pai. Em passagem sugestiva, André descreve-nos que "nunca comemos um pão que não fosse de nossa casa, e é na hora de reparti-lo que concluímos três vezes ao dia o nosso ritual de austeridade, na mesa, onde fazemos de olhos baixos o nosso aprendizado de justiça" (Nassar, 2005, p. 76).

É importante perceber também a figura de André como aquele que consegue, na família, enxergar além do visível; dito de outra forma, a hostilidade invisível da família o invade, provocando uma enorme turbulência. Neste ponto, ele ressalta que

olhando os utensílios da família escuto vozes difusas perdidas naquele fosso sem me surpreender com a água transparente que ainda brota lá do fundo, e recuo em nossas fadigas e recuo em tanta luta exausta e vou puxan- 
do desse feixe de rotinas, um a um os ossos sublimes do nosso código de conduta, o excesso proibido, o zelo, uma exigência condenada como o vício (Nassar, 2005, p. 75).

Assim, percebe-se que André era o único que conseguia ver com mais clareza a 'doença na saúde da família', 'a desordem na ordem da família', como quando afundou a mão no cesto de roupa suja e ouviu o grito de cada um: "era preciso conhecer o corpo da família, cada projeto de homicídio". É interessante perceber que a 'roupa suja da família' pode ser pensada como a possibilidade de deixar-se invadir pelo âmago de cada indivíduo, o mais íntimo, logo, o mais invisível. Desse modo, se a manutenção da limpeza da família só podia ser feita pela concentração da roupa suja em um cesto, sua invasão pode significar um ato de revolta, um perigo mortal para a família (Rodrigues, 2006, p. 66).

Ainda na primeira parte do livro, na qual André encontra-se na pensão conversando com seu irmão Pedro, o nosso personagem principal declara a dor que sentiu ao deixar a mãe, 'a protuberância mórbida do afeto', revelando ao leitor o amor incestuoso que cultivava por ela. Ele afirma que se despediu da mãe apenas com o olhar, sem nada dizer; porém sentira o apelo da mãe pedindo para que ficasse. Neste ponto, declara ao leitor: "A senhora se despede de mim sem me conhecer, quanta coisa eu não poderia dizer à mãe" (Nassar, 2005, p. 64); contudo "achei melhor me guardar trancado; ouvi de seus olhos um dilacerado grito de mãe no parto; não, não faz sentido cortar o cordão umbilical" (Nassar, 2005, p. 65). Ainda fazendo referência ao incesto, conclui que "eu e a senhora começamos a dilacerar esta casa" (Nassar, 2005, p. 66).

Em momentos posteriores da obra, André, no entanto, revela o âmago de seus conflitos interiores, apresentando crises de desejo pela irmã Ana. Em todo seu caos, afirma: "Estou louco". É importante perceber que a descrição do encontro com a irmã na Casa Velha apresenta-se de forma paralela a reminiscências da infância, sobretudo de quando, obstinadamente, tentava capturar uma pomba. Exasperado, afirma que "não se engana nesse incêndio, nesta paixão, nesse delírio!" (Nassar, 2005, p. 96).

Percebemos, pois, que a pomba é uma metáfora da irmã, no sentido de que prendê-la é ter a irmã ao seu lado, ou seja, concretizar um amor impossível. Então, diz a Ana: "decantaremos de numerosos vinhos capitosos, e nos embriagaremos depois como dois meninos, e subiremos escarpas de pés descalços [...] e de mãos dadas, iremos juntos incendiar o mundo" (Nassar, 2005, p. 106). Em suas lembranças, André menino corre com a pomba gritando "é minha!"; posteriormente, ele beija o pássaro e o solta. André, adulto, nos diz "as pombas do meu quintal eram livres de voar, partiam para longos passeios mas voltavam sempre, pois não era mais do que o amor que eu tinha e queria delas" (Nassar, 2005, p. 96). Quando acorda na casa de madeira onde, subitamente, os dois haviam concretizado seus desejos carnais mais íntimos, André percebe que Ana já tinha o deixado.

Dessa passagem, podemos depreender que André percebe a impossibilidade de concretizar seu amor pela irmã em virtude das próprias normas sociais, nas quais o incesto é algo inaceitável. A alternância de cenas da infância com a cena de amor dos dois irmãos revela, contudo, a concretização de um amor puro, advindo de desejos infantis. É a "planta da infância tomando André com o seu viço e sua Constança".

Nesse momento, André revela a Pedro o motivo real pelo qual havia fugido de casa: "Era Ana, Pedro. Era Ana, minha fome, era Ana minha enfermidade, era ela a minha loucura, ela o meu respiro, a minha lâmina, meu arrepio, meu sopro, o assédio impertinente dos meus testículos" (Nassar, 2005, p. 107). André, em um acesso de desespero, continua: "era eu o irmão acometido, era eu o irmão exasperado, era eu o irmão de cheiro virulento, era eu que tinha na pele a gosma de tantas lesmas, a baba derramada do Demo" (Nassar, 2005, p. 108). Assim, André pede a Pedro que o limpe, pois caberia a ele fazê-lo: "É isto que compete a você, Pedro, [...] a você que foi brindado com a santidade da primogenitura" (Nassar, 2005, p. 106).

Nesse momento do livro, instala-se um conflito, o caos identitário do narrador personagem:

Mas na corrente do meu transe já não contava a sua dor misturada ao respeito pela letra dos antigos, eu tinha de gritar em furor que a minha loucura era mais sábia que a sabedoria do pai, que a minha enfermidade me era mais conforme que a saúde da família, que os meus remédios não foram jamais escritos nos compêndios, mas que existia uma outra medicina (a minha!), e que fora de mim eu não reconhecia qualquer ciência e que tudo era só uma questão de perspectiva (Nassar, 2005, p. 109).

Porém, o que podemos perceber é que, mesmo discordando da ordem familiar, ele se considerava sujo, o 
pervertido da família. Dizia em seus acessos que era um 'epilético' eu berrava e soluçava dentro de mim, sabendo que atirava numa suprema aventura ao chão, descarnando as palmas, o jarro da minha velha identidade elaborado com o barro de minhas próprias mãos" (Nassar, 2005, p. 39). Mais uma vez, evidencia-se o conflito vivido por André no que tange ao seu distanciamento de qualquer moral da família. Falta-lhe um referencial no qual pudesse sustentar uma identidade que foge à singularidade do seu contexto social.

André declara: "amar e ser amado era tudo o que eu queria, mas fui jogado a margem sem consulta, fui amputado" (Nassar, 2005, p. 137). 0 conflito enlaça André e o coloca a seguinte questão: caberia sustentar o amor incestuoso à custa da perda do amor e reconhecimento da família? Revelando sua dor, afirma: "pertenço como nunca a essa insólita confraria dos enjeitados, dos proibidos, dos recusados pelo afeto, dos sem-sossego, dos intranquilos, dos inquietos, dos que se contorcem" (Nassar, 2005, p. 138). É importante perceber nesses fragmentos a turbulência que permeia a identidade de André.

Segundo Ciampa (2004, p. 70)

só posso comparecer no mundo frente a outrem efetivamente como representante do meu ser real quando ocorre a negação da negação, entendida como deixar de presentificar uma apresentação de mim que foi cristalizada em momentos anteriores, deixar de repor uma identidade pressuposta, ser movimento, ser processo, ou, ser metamorfose.

Logo, percebemos que a identidade de André na infância, considerada escura e inocente, deixa de ser confirmada como conivente com os papéis sociais a que dele se esperava (baseado na palavra do pai), passando, na adolescência a ser 'arredio', a ser metamorfose. 0 amor proibido pela irmã levou-o a questionar os próprios princípios que sustentavam a família patriarcal, a hipocrisia da moral religiosa, segundo a qual a família jamais abandonaria um filho desgarrado. Porém os valores dessa família esmagam o filho pródigo, o amputam perante os próprios desejos.

\section{Retorno: é possível romper com os desígnios do tempo?}

que eu, a cada passo, me distanciava lá da fazenda, e se acaso distraído eu perguntasse 'prá onde estamos indo? '- não importava que eu erguendo os olhos, alcançasse paisagens muito novas, quem sabe menos ásperas, não importava que eu, caminhando, me conduzisse para regiões cada vez mais afastadas, pois haveria de ouvir claramente de meus anseios um juízo rígido, era um cascalho, um osso rigoroso, desprovido de qualquer dúvida: 'estamos indo sempre para casa' (Nassar, 2005, p. 34).

A segunda parte do livro começa, como já foi dito, com o retorno de André à casa dos pais, acompanhado por seu irmão Pedro. Esse retorno pode ser considerado o ápice da história no sentido de que possibilita o 'acerto de contas' entre pai e filho. André foi recebido com muita alegria, pois o reencontro representou para a família a volta do filho 'perdido' ao recôndido lar. Nesse momento, a família já planejava a festa para comemorar o retorno do filho 'pródigo'.

Após um período de descanso, André é chamado para conversar com o pai, que lhe pede que fale com clareza os motivos pelos quais abandonou a 'família'. André diz ao pai que nunca havia pensado em abandonar a casa, porém não esperava encontrar lá fora aquilo que lhe faltava no lar. 0 pai, exaltado, não consegue entender o que o filho está dizendo e exige que o mesmo coloque suas ideias em ordem. André ressalta ao pai que "cada ordem traz em si uma semente de desordem, a clareza, uma semente de obscuridade" (Nassar, 2005, p. 158).

André diz que busca um "lugar à mesa da família"; Yohana, no entanto, reafirma que todos os filhos sempre participaram da distribuição do pão; portanto, o lugar à mesa da família nunca lhe havia sido negado. André retruca que participar apenas da repartição dos pães era um ato de crueldade, pois alongava mais a sua fome. 0 pai, agitado, o acusa de blasfemar, afirmando que ele está enfermo e que somente o trabalho quebrará o orgulho da sua fala e ele devolverá a saúde. 0 filho, mais uma vez, questiona que "não se interessa por essa saúde que traz em si uma semente de enfermidade". Neste ponto, é importante ressaltar que o pai mostra-se nervoso com os questionamentos de André, não compreendendo, ou melhor, não se deixando contaminar pela argumentação ferrenha do filho. Nesse sentido, Yohana ordena a André que esqueça os seus caprichos, pois "não há proveito em atrapalhar as ideias da família".

Em suma, podemos relacionar essa parte do livro com o choque entre o homem da moral e o homem da ética. 0 pai, representante do homem da moral, não 
se deixa permear pelo invisível e, quando este o invade, interpreta os seus efeitos a partir dos códigos morais. Dessa forma, o pai afirma não compreender aquilo que o filho está a lhe dizer e, quando apreende algum sentido, diz não acreditar, construindo como um mecanismo de defesa algo imaginário que o conforta: meu filho está doente. Já André pode ser considerado o homem da ética, no sentido de que consegue enxergar além do visível, por entre as "frestas" da janela, dando um caráter novo a composições arcaicas. Assim, para Rolnik (1994, p. 166),

o homem da ética transita no invisível, é ele quem escuta as reverberações das diferenças que se engendram no nosso inconsciente e a partir daí nos leva a tomar decisões que permitem a encarnação de tais diferenças em um novo modo de existência, tanto no sentido de fazer novas composições, quanto no sentido de desmanchar composições vigentes.

Desse modo, André encarna a diferença, tornando-se outro, diferente de todos os integrantes de sua família. É possível, então, entender com clareza a dificuldade de comunicação entre o homem da moral e do homem da ética, já que, enquanto o primeiro se prende às composições vigentes como defesa contra o caos, o segundo está sempre imerso na turbulência.

Diante do descrédito do pai, André enfatiza que "não se pode esperar de um prisioneiro que sirva de boa vontade na casa do carcereiro, assim como, pai, de quem amputamos os membros, seria absurdo exigir um abraço de afeto" (Nassar, 2005, p. 162). Segundo o nosso personagem, "mais pobre o pobre que aplaude o rico, menor o pequeno que aplaude o grande [...] Imaturo ou não, não reconheço mais os valores que me esmagam" (Nassar, 2005, p. 162). 0 pai, ainda sem entender, pergunta enfaticamente de quem ele está falando. 0 filho, por sua vez, responde que não está falando de "ninguém em particular"; porém, fala dos "desenganados", dos "sem remédios", "dos que gritam de ardência, sede e solidão" (Nassar, 2005, p. 163).

Yohana desiste de entender André, afirmando que a 'família' não é um ambiente hostil. 0 filho acrescenta enfaticamente que "a realidade não é a mesma para todos [...]" (Nassar, 2005, p. 164). Diante de tal revelação, o pai dá um murro na mesa, dizendo que sempre houve amor, e jamais hostilidade, na família. André declara que o amor, no entanto, pode ser uma pedra no caminho, já que também desune. Yohana exige que ele se cale e, definitivamente, que seja simples. André diz que seria inútil, já que mesmo que depositasse sobre a mesa um ramo de oliveira, o pai poderia ver somente um ramo de urtiga. 0 pai, mais uma vez exasperado, reafirma veementemente os valores da casa, desconsiderando o discurso de André.

Essa passagem demonstra de forma bastante clara a impossibilidade da comunicação entre o pai e o filho, no sentido de que o primeiro não é capaz de ir além dos próprios princípios para ver a família sob outra perspectiva; aliás, para o homem da moral, não há espaço para pontos de vista divergentes.

Em meio a esse tenso diálogo entre pai e filho, a mãe, que até então permanecera em silêncio, interfere na conversa em favor a André, pedindo ao marido, Yohana, que o poupasse. É importante ressaltar que esse foi o único momento em que aparece o nome do pai no livro. Tal fato demonstra, mais uma vez, como ele está confundido com o seu papel social, já que as semelhanças identitárias com os seus antepassados são mais enfatizadas do que aquilo que o diferencia dos demais. Assim, como já foi explicitado anteriormente, o pai confunde-se com a figura do avô, assim como Pedro confunde-se com Yohana.

Diante do apelo da mãe, André finalmente se rende ao homem da moral, pedindo perdão ao pai. Afirma voltar à casa humilde, submisso, dedicando-se ao trabalho com afinco, como seus irmãos. 0 pai, muito emocionado, diz que fará uma festa para comemorar a volta do seu filho "que estava cego e recuperou a vista" (Nassar, 2005, p. 169). Neste ponto, é importante destacar a figura do irmão mais novo de André, Lula, que logo o confessa que também fugirá de casa por não aguentar a rigidez do pai, declarando que não falhará como ele.

A festa dedicada a André representa a última cena do livro, na qual Ana, utilizando os adereços de prostitutas da maleta trazida pelo irmão, toma de assalto a festa, dançando de forma sensual. Em transe profundo, ninguém conseguia contê-la, até que o irmão mais velho Pedro, desnorteado, convoca o pai para fazer valer os princípios morais da família. Yohana, vendo a filha se comportar como uma prostituta, impulsivamente lança mão de um alfanje e, num gesto abrupto, põe fim à cena, juntamente com a vida da "dançarina oriental" (Nassar, 2005, p. 191). Na última fala do livro, Lula, desesperado, grita: "E a nossa família, pai?".

A figura de Pedro ao término do livro, como aquele que convoca o pai, demonstra o seu papel de 
primogênito, ou seja, daquele que o substituirá após sua morte, fazendo valer os códigos do homem da moral. É também interessante perceber a figura de Lula, pois o mesmo abre a possibilidade de continuação da história, na medida em que insere mais uma vez na trama o homem da ética, em seu infinito combate com o homem da moral. Dessa forma, ele, em sua frase final, propõe um questionamento no que tange a falta de limites do homem da moral na sua busca incessante pela manutenção da ordem social.

Quanto ao desfecho da obra, cabe ainda destacar que André rende-se não às incoerências do pai, mas ao apelo da mãe, com a qual mantinha uma relação um tanto quanto incestuosa. Desse modo, a relação do personagem com a mãe sempre fora, desde a mais tenra infância, marcada pelos carinhos sensuais, pelo 'excesso' pulsional, e é exatamente a essa felicidade da infância que André não renunciou, deslocando-a para a figura da irmã Ana.

Conforme nos aponta Freud, os primeiros objetos de investimento libidinal da criança são os pais e cabe a ela, com a sua entrada na cultura, abrir mão de seus desejos incestuosos a fim de manter o pacto social. Para esse mesmo autor, na dissolução do Complexo de Édipo,

as catexias de objeto são abandonadas e substituídas por identificações. A autoridade do pai ou dos pais é introjetada no ego e aí forma o núcleo do superego, que assume a severidade do pai e perpetua a proibição contra o incesto, defendendo assim o ego do retorno da catexia libidinal (Freud, 1924, p. 196).

Dentro desse viés de análise, podemos dizer que André está em contato com o que há de mais arcaico na constituição subjetiva, com aquilo que cada sujeito teve que renunciar de alguma forma, mesmo pagando um preço relativamente elevado. Para ele, o amor de Ana está no início, calcado na sedução e no viço da infância, "ele é o núcleo, ele é a semente, o seu amor é o princípio do mundo" (Nassar, 2005, p. 128). Para Freud, o resultado final da entrada do homem na civilização é "um estatuto legal para o qual todos - exceto os incapazes de ingressar numa comunidade - contribuíram com o sacrifício de seus instintos, que não deixa ninguém - novamente com a mesma exceção - a mercê da força bruta" (Freud, 1930, p. 102).

0 amor incestuoso coloca o personagem principal em sintonia com o próprio corpo, palco dos desejos mais primitivos. Em toda a obra é possível perceber o quão o sofrimento de André é demonstrado no âmbito de seu próprio corpo. A febre que ele sentia só podia ser aliviada por meio do contato físico com a terra úmida e do ato de cobri-lo com as folhas das árvores. Essa cura, apesar de momentânea, levava-o a uma busca por uma fusão com a própria natureza (Rodrigues, 2006, p. 69).

Há, pois, uma oposição clara na obra entre o meio natural e a família, representante da cultura. 0 meio familiar, visto sob arcaicos preceitos morais, buscava domar qualquer expressão do retrocesso do homem à natureza, ao primitivo não mediado pela cultura. "Preocupada em mantê-lo distante de uma vida mais pura, mas talvez incontrolável e ingovernável, a família protege, isto é, vigia, e assim mantém, ou até mesmo aumenta, a cisão, a fratura entre o "eu" e a natureza" (Rodrigues, 2006, p. 69).

O fim do livro surpreende pelo fato de que André abdica de seus questionamentos em favor do amor à mãe e se deixa dominar pelo homem da moral. Desse modo, se é pelo amor à mãe e à irmã que ele extravasa 'as cercas da casa', é também pelo mesmo afeto que ele aceita se submeter, 'obediente' aos princípios da família. Nessa perspectiva, conforme nos aponta Freud, é apenas por amor que um indivíduo é capaz de abrir mão de sua distintividade em um grupo, acatando os seus preceitos (Freud, 1921, p. 103). E é também pelo medo da perda do amor dos pais, na "planta da infância", que a criança é capaz de renunciar aos seus desejos incestuosos e inserir-se na cultura.

Podemos pensar, tendo como base o desdobramento da história, que é no instante em que a mãe se interpõe em sua defesa que ele de fato assume o pacto social e se submete aos princípios da fazenda. Após o retorno para casa, ele se dá conta de que "a sabedoria está precisamente em não fechar nesse mundo menor: humilde, o homem abandona sua individualidade para fazer parte de uma unidade maior, que é de onde se retira a grandeza" (Nassar, 2005, p. 146). É como se nesse momento, André estivesse assumindo para si as exigências da civilização, a renúncia de seus desejos incestuosos pela irmã Ana. A partir daí ele pôde voltar "para casa humilde, submisso", pois, conforme afirma, "não tenho mais ilusões, já sei o que é solidão, já sei o que é miséria, sei também agora, pai, que não devia ter me afastado um passo sequer da nossa porta" (Nassar, 2005, p. 168).

Nessa medida, mesmo distanciando-se dos valores familiares, localizando neles a pura contradição, 
havia sempre nos anseios mais íntimos de André um "juízo rígido", um "cascalho", um "osso rigoroso" que sempre lhe trazia de volta para as cercas da fazenda nos momentos de suas pequenas fugas. Esse ir e vir, essa partida e esse retorno marcam a sua história, na medida em que a negação desses valores arcaicos, dos sermões na mesa do pai, revela antes de tudo a presença, a introjeção dos mesmos.

Dessa forma, a busca de André em 'ser profeta da própria história', a construção de sua alteridade, requer principalmente uma luta incessante nessa lavoura arcaica: é, antes de tudo, a marca de pequenas fugas das cercanias da casa, acompanhada de pequenos regressos incontornáveis.

\section{Referências}

Ciampa, A. C. (2004). Identidade. In S. T. M. Lane \& W. Codo. (Org.). Psicologia social: 0 Homem em movimento (pp. 58-75). São Paulo: Brasiliense.
Freud, S. (1921). Psicologia de grupo e Análise do eu. (Vol. 18). Rio de Janeiro: Imago.

Freud, S. (1924). A dissolução do Complexo de Édipo. (Vol. 19). Rio de Janeiro: Imago.

Freud, S. (1930). 0 mal-estar na civilização. (Vol. 21). Rio de Janeiro: Imago. (Originalmente publicado em 1929).

Nassar, R. (2005). Lavoura arcaica. Edição Comemorativa 30 anos (1975-2005). São Paulo: Companhia das Letras.

Rodrigues, A. L. (2006). Ritos da paixão em Lavoura Arcaica. São Paulo: EDUSP.

Rolnik, S. (1994) Cidadania e alteridade: 0 psicólogo, o homem da ética e a reinvenção da democracia. In A.V. Mautner \& M. J. Spinck. (Org.). A cidadania em construção: Uma reflexão transdisciplinar (pp. 157176). São Paulo: Cortez.

Sedlmayer-Pinto, S. (1997). Ao lado esquerdo do pai. Belo Horizonte: Ed. UFMG. 
